\section{Librarianship in the Proprietary Education Context}

\section{Eric Rector}

Eric Rector is Director of Library Services, American National University.

Correspondence concerning this column should be addressed to Marianne Ryan, Associate University Librarian for User Service Strategies, Northwestern University, 1970 Campus Drive, Evanston, IL 60208; email: marianne-ryan@northwestern.edu.
For a variety of reasons, many of us have never considered librarianship in the for-profit sector. But as proprietary education continues to expand its reach, providing information services in that environment affords a range of new possibilities. In this column, Eric Rector presents an overview of what it's like to manage a library at a for-profit institution. In a well-crafted overview of the proprietary context, he highlights both its challenges and opportunities. His frank perspectives offer a worthwhile alternative to working in a traditional-education setting. Rector makes a compelling argument for proprietary librarianship, suggesting that it may well be worth thinking about.-Editor

t wasn't my plan to work in proprietary education. Then again, it wasn't my plan to work for a consortium, or a database provider, or as an IT director at a medical school whose charter class had not yet matriculated. I chose those positions because each one provided an exciting opportunity to grow professionally and because they captured my imagination. Similarly, my move to proprietary education did not disappoint. Whether you are a new librarian in search of your first position, or a seasoned professional seeking a new challenge, proprietary education may be worthy of consideration.

The goal of this article is to discuss the challenges and benefits of being a librarian at a for-profit institution, to provide some idea of what you might reasonably expect from the sector, both as a manager and as a subordinate, and to present some ideas on delivering quality reference services to the populations you would likely be serving. Of course, the ideas presented here are based on my own experiencessaying all for-profit schools are alike would be like saying all liberal arts colleges are the same-and each institution will have its own unique elements.

\section{THE FOR-PROFIT SECTOR}

So just what is proprietary education? For starters, there are two broad categories: public and private. Not unlike publicly traded companies, public for-profits have a board of directors and shareholders who participate in determining the institution's direction, whereas private for-profit institutions are owned by individuals or small groups and do not publicly trade their stock. While I use the terms "for-profit" and "career education" interchangeably in this article, the two are not necessarily synonymous. Proprietary education spans every level of higher education, from trade schools and 
technical colleges to career colleges and doctoral-granting institutions.

The curriculum itself may be delivered completely online, in-person, or using a hybrid model. As for the libraries at for-profit institutions, I have little doubt that many of them still resemble the libraries that Davis, Adams, and Hardy describe in their evaluation of academic libraries in the for-profit sector. ${ }^{1}$ However, the political and economic pressures of the last decade, coupled with rising technological fluency across the population, are leading administrators of these schools to make, or continue to make, enhancements to library services, leading to an exciting time of change and growth in proprietary librarianship.

Although vocational/career/trade education has had national support in the past, over the last decade it has gained the reputation of being, at best, slightly below board and, at worst, predatory. ${ }^{2}$ While it's true that some players in the market have behaved badly, others are sincerely engaged in the "business" of providing streamlined education for those who need or desire it, many of whom might not attend college otherwise. Among career academics, there seems to be a sense that the for-profit sector is "other," but, in my experience, there are strong similarities between for-profit education and traditional higher education, school media centers, medical education, and, not surprisingly, the corporate environment. Furthermore, it is not uncommon for larger universities to have research parks and technology incubators, and there is no doubt that college sports are money-making enterprises. Indeed, even with regard to the curriculum, there is a growing dependence in nonprofit education on for-profit educational curriculum products, such as Pearson's CourseConnect, which blurs the lines even further. ${ }^{3}$

\section{MODERATING EXPECTATIONS}

If you are considering a move to a for-profit institution, understanding what you may encounter should help you avoid surprises. Let's start with compensation and benefits. You can expect that compensation will be on par with nonprofit institutions, and that it will be closely aligned to regional salaries for equivalent positions. Where you will probably see a major departure from traditional educational institutions, though not necessarily the corporate environment, is in benefits. The largest disparity is time off. In this area, forprofit institutions show their corporate stripes. This is in part because the business model stresses quick degree completion, which requires a year-round academic calendar. You can expect a modest accrual of sick leave and vacation time, and significantly fewer holidays off. No spring break. No closing between Christmas and New Year's Day. You should find the health benefits adequate, but you may not have the variety of choices you would at a large, state institution. For anyone who has worked outside of traditional higher education, this won't come as a surprise and it won't affect your ability to deliver services, but it is a point of consideration.
What may be more impactful is the for-profit institution's goal of making a profit. For the library, that means attempting to reach peak efficiency in building collections and providing services. I'll discuss both of these in-depth later, but it's important to understand that you won't find much latitude in this area. To be successful, you'll need to buy into the idea of getting the most out of your collections and staffing budgets. I find it helpful to keep in mind that most of the institution's income comes from tuition, and that any costly improvements may directly affect tuition or the bottom line. On the plus side, value is placed on those positions required to deliver the product, and library services are definitely included in that! Indeed, accreditors require that library collections be overseen by a professional librarian, and often require proof of library-related projects in students' coursework.

Most in higher education are familiar with the rapid rise of large, publicly traded for-profit institutions, some of which have recently failed, leaving students and taxpayers in the lurch. This has led to discussions at the Department of Education about "forbidding schools from requiring students to sign an arbitration clause before they enroll" to earn debt forgiveness more easily, which could negatively affect many for-profit institutions. ${ }^{4}$ Additionally, for several years, the department has been moving toward requiring for-profit schools to demonstrate that their graduates meet the criteria for gainful employment, which means, in a nutshell, that they are employed in the recognized occupation for which they earned their degree. ${ }^{5}$

These rulings and requirements may have a cascading effect at an institution. Time, money, and effort that could be put toward enhancing the curriculum, purchasing equipment, and providing additional library resources may instead be spent tracking graduates' employment, pursuing students who are not repaying loans, and other such administrative tasks. However, many forward-thinking proprietary institutions are taking this opportunity to enhance student services. Examples from my institution include investments in career services software and staffing and a substantial investment in library collections and services, both of which are aimed at providing "high tech, high touch" services to students in an effort to help them succeed both in their course work and in finding employment after graduation.

Finally, on a personal level, moving into proprietary education may feel like being an outsider in your profession, at least at first. Although you may encounter some resistance from your current colleagues when you tell them you're considering a for-profit school, you will most likely find more internal resistance, especially if you have only been a traditional academic librarian. There has been, after all, a significant amount of bad press about the sector, and you may have even cast a disparagement or two yourself. If your identity is strongly aligned with what you see as the "ideal" delivery of education, which I would argue doesn't actually exist in the real world, it may be hard for you to come to terms with the idea of higher education as a for-profit enterprise. In reality, 
proprietary librarianship offers the same, if not better, opportunities to build collections, teach information literacy, and affect the curriculum, as long as you are willing to work within the for-profit construct.

I have, however, been surprised by the lack of opportunities to interact with other for-profit librarians thus far. I saw no programs or meetings at the 2016 ALA Annual Conference, and the traffic on ACRL's Librarianship in For-Profit Educational Institutions (LF-PEI) Interest Group electronic discussion list has been light. It could be a matter of timing, since the LF-PEI group was clearly active in 2014-15, hosting two virtual conferences, and there is an meeting scheduled at the Virginia Library Association in October, 2016. It is also possible that librarians from the sector are merely identifying with the larger academic library community and finding connections and opportunities there. Regardless, I'm hopeful that there will be more opportunities in the future.

\section{SERVICES}

Not unlike corporate libraries and school media centers, librarianship at for-profits is tightly associated with providing services aimed at helping students complete their courses. The for-profit curriculum is by nature career-based, resulting in significantly fewer general education requirements and courses. The required courses related to the academic programs tend to be standardized across sections and campuses (in a multi-campus environment). This is a departure from traditional education as I experienced it, but it is a powerful aid in delivering library services. There are no mysterious classes with assignments that will take you by surprise and, depending on the institution, the library may have access to the syllabi for every class being taught! Because of this, the library is able to provide highly tailored, pre-recorded tutorial sessions, handouts, and subject guides to meet the needs of students in a particular class. Depending on the institution, you may also find yourself in the enviable position of being able to suggest information literacy and library modules to add to the general curriculum, resulting in sweeping exposure to information literacy concepts.

One thing that rapidly becomes apparent is that, with the focus on career education and training, classes are mostly applied and are generally taught by professionals in the field. The friction between full-time faculty and administration over the use of adjuncts and curricular issues is largely absent. For those in the medical library sector, I find that the teaching model closely resembles how much medical education is delivered through faculty preceptors. In my experience, medical schools employ full-time faculty to teach core courses and develop the curriculum, but much of the students' education is delivered by adjuncts and clinical faculty at the point of health care delivery in accordance with curricular goals established centrally. The preceptor teaching model is not only common, but widely accepted and even embraced. Similarly, when delivering applied, career education, the real-life experience of professionals from the field is invaluable, and those professionals appear to welcome the centralized structure.

The adjunct model does affect library services in subtle ways. For instance, adjunct faculty may be interested in library services, such as instruction for classes, but they are not always easy to reach because they are employed full-time elsewhere. There are fewer committee requirements for the teaching faculty as well, so you may need to consider that if you are planning a library advisory committee on which you want faculty participation. You should be prepared for low turnout but high levels of enthusiasm.

Students enrolled in for-profit programs tend to be hightouch. While eager to succeed, they most likely have not been academically accomplished, may have graduated college years earlier, and are returning to advance or change their careers. I started my career in a library at a researchintensive university in 1997. At that time, many of the students struggled with the technology. They had little or no experience searching online databases; only a handful of our indexes were available on CD-ROM then. Those students were, by necessity, high-touch. Depending on the for-profit institution, there's a distinct possibility that the students will be unaccustomed to using the library resources that many incoming traditional freshmen have had exposure to in high school. That goes for students who are taking online classes as well. They may be comfortable navigating the learning management system, but they may also struggle when they move outside of the system and into the library databases or catalog. You'll need to be prepared to create tutorials and handouts that help students bridge the gap, and hopefully you'll have opportunities to connect with them in real-time to introduce them to the library's resources.

Information literacy, critical thinking, and lifelong learning are all important in the delivery of career education. However, as stated earlier, there are fewer general education courses through which to get our foot in the door, and the students themselves may not be interested in becoming information literate because they see it as superfluous to their career needs. They are, after all, taking classes so that they can find a better job. But that does not mean the concepts of information literacy can't be successfully addressed. In the current environment, it's likely that your institution will be receptive to the idea of information literacy; you may even find that your for-profit institution has a first-year program. If not, don't fret. You may have many opportunities to create materials addressing information literacy, and you'll be able to work it into your classes quite easily. However, don't be surprised (or discouraged) if your large-scale information literacy program doesn't get the green light. Administration and faculty may support the idea of information literacy, but they are charged with delivering a product to students who, again, have career advancement in their sights.

When it comes to library services, small proprietary institutions can be extremely agile. A high value is placed on efficiency, autonomy is encouraged, and the organizational 
hierarchy is relatively flat. That equates to the possibility of rapid change without resistance, as long as you can demonstrate improvement of services, cost savings, or efficiency. For example, because many of the faculty are adjunct, they are focused on delivering the content to their students and helping those students succeed. But because they are not necessarily heavy library users themselves, I have found it significantly easier to make changes to the library's web presence without major fallout. Students enrolled at forprofit institutions are not likely to be avid library users, either. That means they may not be vocal about changes, but it also means that we need to take every opportunity to provide clear, simple explanations of library resources whenever possible.

Twenty years ago we had limited tools we could provide library users. Today, we have more intuitive tools that simplify searching and excel at recall, if not precision. What the new discovery layers and multidisciplinary databases do best, in my opinion, is get the students into the information, not unlike jumping into the deep end of a pool. This has encouraged my librarians to design systems and services with low entry points so we can get the students on their way to swimming laps. Simplifying entry points also helps with our students' short attention spans and relatively low tolerance for complication. It has also challenged us to develop ideas for information literacy that begin with the older, more concrete standards, before incorporating the new information literacy framework. Regardless of the type of for-profit, you can expect the students will be hard working but distracted, and that they will have a much more practical than academic take on education.

\section{COLLECTIONS}

Unlike larger universities or even liberal arts colleges, forprofit collections tend to be much narrower in scope and more practical in nature, not surprisingly since the curriculum is much more focused on career-related degrees. That being said, some larger for-profits will almost certainly have collections, especially electronic ones, which rival those available at nonprofit institutions. However, many of the wonderful, reasonably priced, primary source collections may be a hard sell for your administration and, I would argue, simply have no place in most career college collections. By necessity, proprietary library collections should be lean, responsive, and "right-sized," aimed at providing relevant materials that aid students in completing the curriculum. ${ }^{6}$ Still, there are ample opportunities to provide students access to literature, philosophy, and like materials that encourage critical thinking and lifelong learning. Indeed, accreditors require such material be available to students and expect to see evidence of curricular activities involving the library, as well as evidence of the library's responsiveness to student and faculty requests.

I am confident in saying that most for-profit libraries are without a collection development policy. However, given the nature of the sector, and the expectation for efficiency in collections, it is important to have a well-articulated policy or, at the very least, a consistently articulated approach to which materials should be selected, in what format, and to what extent. If your delivery of library services is distributed, it is especially important to have a clear understanding across campuses and libraries. If the institution, or each individual campus, has a physical collection, a clear gift policy is imperative. It can be tempting to bulk up campus collections with materials like gift books and videos, but that is ultimately counterproductive and a disservice to users. Keeping the collection lean is critical to meeting programmatic needs efficiently.

Given the distributed nature of proprietary education, and the tendency toward providing many classes online, it's not surprising that the majority of your collection may be electronic. It may be appealing to buy large, multidisciplinary e-book products, but efficiency dictates that selecting a few, discipline-focused collections is a better place to begin. Again, given the applied nature of most for-profit programs, expansive collections are probably a poor use of library dollars. Consider, instead, investing in tools that will help your students with writing, math, résumé writing, and testing. When it comes to large, multidisciplinary databases, it is best to concentrate on ease of use and recall, rather than advanced capabilities and indexing, although providing higher quality tools, if they are within budget, can also offer opportunities for instruction.

Obtaining reasonable pricing for electronic resources can be a challenge. For instance, if an institution has multiple campuses, vendors may insist on applying tiered-pricing by campus or groups of campuses. For a small, multistate institution, this can result in a product being several times more expensive than if pricing was based on the institution's total FTE (Full-Time Equivalent Enrollment), which effectively eliminates any chance of purchase.

Consortial purchasing options may also be limited, as some state-funded purchasing consortia will not allow propriety institutions to participate, even as a buyer's club member, because of their for-profit status. However, many corsortia, such as Lyrasis and the Library and Information Resources Network (LIRN), as well as many state consortia, do work with all educational institutions and are invaluable in maximizing the library's purchasing power. Many vendors also take the structure and population of the institution into account and price their products accordingly. Building relationships with those vendors can result in a partnership that is highly beneficial to both entities.

\section{THE RIGHT PERSON}

During my time in the proprietary sector, I have observed many librarians who demonstrate qualities that have made them successful. Those include self-confidence, a desire to learn and to help others learn, a decided self-starter 


\section{MANAGEMENT}

mentality, and the ability to adapt quickly and to accept and work within the parameters of a for-profit business. Those librarians have also been quick to recognize that students who enroll in for-profit schools face substantial challenges but are determined to make the most of their opportunity.

Thriving as a proprietary librarian requires energy and pragmatism. For-profit schools have experienced their share of financial and political challenges but remain focused on delivering an educational product to a consumer who is eager to learn trade skills and improve career opportunities. In for-profit education, efficiency is a key measure of success, and understanding the institution's priorities can help guide the library in making choices that adhere to the bottom line while meeting programmatic needs and serving the students and faculty. The sector is beginning to change, and it's not hard to imagine that it will soon be seeking librarians with a broad range of skills who are open to the challenge of delivering library services in a for-profit environment. Perhaps you are one of them?

\section{References and Notes}

1. Jinnie Y. Davis, Mignon Adams, and Lee Hardesty, "Academic Libraries in For-Profit Schools of Higher Education," College $E$ Research Libraries 72, no. 6 (November 2011): 568-82, ProQuest (909813645)
2. For a historical overview, see Ernest C. Brewer, "The History of Career and Technical Education," in Definitive Readings in the History, Philosophy, Practice and Theories of Career and Technical Education, edited by Victor C. X. Wang (Hershey, PA: IGI Global, 2010), 1-16. For an example of the sector's political challenges, see Neal McCluskey, "For-Profit Colleges: Terrible or Target?," CATO at Liberty (blog), June 22, 2016, www.cato.org/blog /profit-colleges-terrible-or-target.

3. Goldie Blumenstyk, "How For-Profit Education is Now Embedded in Traditional Colleges," Chronicle of Higher Education, January 15, 2016, Al3.

4. Ann Larson, "Obama's Missed Chance to Help For-Profit College Students," Politico June 14, 2016, www.politico.com /agenda/story/2016/06/department-of-education-rule-for-profit -college-000145

5. For more information, see "Gainful Employment," US Department of Education, July 1, 2015, www.ed.gov/category/keyword /Gainful-Employment; "Program Integrity: Gainful Employment," 79 Fed. Reg. 64890 (October 31, 2014).

6. The idea of right-sizing library collections has become increasingly popular in the last few years. For an excellent overview, see Suzanne M. Ward, Rightsizing the Academic Library Collection (Chicago, ALA Editions, 2015). 